\title{
World climate services framework agreed
}

GENEVA

A global framework to supply on-demand climate predictions to governments, businesses and individuals is moving closer to reality.

On 3 September, delegates representing 155 nations at the World Climate Conference in Geneva, Switzerland, agreed that a body should be established to supply such 'climate services' to users ranging from national governments to individual farmers. The service would be particularly helpful for developing nations, many of which lack access to the weather and climate observations needed to plan their strategies for adapting to climate change.

Over the next four months, an independent task force set up by the World Meteorological Organization will work out how to make this vision a reality. A 12-month consultation process with signatory nations will follow.

"It's about time we got serious," says climatologist Jonathan Overpeck of the University of Arizona in Tucson. "We can save wealth and properties if we get climate information into the hands of decision-makers."

But a global climate service will face a host of scientific and political hurdles. Negotiating data collection and sharing among member states will be a big challenge, for example. Some countries are already baulking at the suggestion that they will need to supply the service with data, citing issues such as national security or commercial interests that would prevent disclosure. In response, Martin Visbeck of the Leibniz Institute of Marine Sciences at the University of Kiel in Germany says that one option would be to allow "data of convenience tailored for specific purposes [to] be commercialized", while allowing "fundamental information to be freely available".

Climate scientists will also have to improve the quality of the climate projections that the service could provide. Today's global climate models predict how climate variables, such as temperature and rainfall, will change over the coming century at scales of several hundred kilometres. But scientists are hopeful that with further research they could bring that down to just tens of kilometres, covering timescales of a decade or less.

In the meantime, individual nations are forging ahead with their own climateservices centres. In July, Germany opened a centre in Hamburg, and the United States is discussing a national climate service. Olive Heffernan

For a longer version of this story, see http://tinyurl.com/climate-service.

Correction

The News Feature 'Last chance clinic' (Nature 460, 1071-1075; 2009) inadvertently located Massachusetts General Hospital in Cambridge. It is in Boston. 